\title{
Pancreatic Anastomosis Healing
}

\author{
Stanislaw Hac ${ }^{1 *}$, Rafal Peksa ${ }^{2}$, Marek Dobosz ${ }^{3}$, Tomasz Wysocki ${ }^{3}$, Pawel Lampe ${ }^{4}$, \\ Katarzyna Kusnierz ${ }^{4}$, Pawel Mroczkowski ${ }^{5}$, Zbigniew Sledzinski ${ }^{1}$ \\ ${ }^{1}$ Department of General, Endocrine \& Transplant Surgery, Medical University of Gdansk, Gdansk, Poland; ${ }^{2}$ Department of Pathol- \\ ogy, Medical University of Gdansk, Gdansk, Poland; ${ }^{3}$ Department of General Surgery, Gdansk Municipal Hospital of Gdansk, Divi- \\ sion of Surgical Nursing, Medical University of Gdansk, Gdansk, Poland; ${ }^{4}$ Department of Digestive Tract Surgery, University Hos- \\ pital of the Medical University of Silesia, Katowice, Poland; ${ }^{5}$ Department of Vascular and Visceral Surgery, Otto-von-Guericke Uni- \\ versity, Magdeburg, Germany. \\ Email: ${ }^{*}$ sthac@gumed.edu.pl
}

Received April 25 $5^{\text {th }}, 2012$; revised May 21 ${ }^{\text {st }}, 2012$; accepted June $7^{\text {th }}, 2012$

\begin{abstract}
Background: Pancreatoduodenectomy (PD) is a complex procedure with a relatively high risk of complications. There is an increasing trend showing that the success of pancreato-enteral anastomosis depends on surgical skill and the material used. Methods: We present four cases of pancreato-enteral anastomosis resected 37 - 114 days after primary surgery and the analysis of the healing process, i.e., morphology of the pancreatic parenchyma, pancreatic duct, and digestive tract mucosa, as well as the pancreatic reaction to the sewing material by microscopic morphometry. Results: Evidence of regeneration in the columnar-lined mucosa of main pancreatic ducts in all cases of pancreato-enterostomy was observed. The inflammatory foreign-body reaction around monofilament stitch was present without an evident infection. There were no microscopic signs of pancreatic duct damage. Total foreign body reaction varied between $138.1 \mu \mathrm{m}$ and $207.3 \mu \mathrm{m}$. Conclusions: This observation supports the beneficial use of thin monofilament threads for pancreato-enteral anastomosis. There was no evidence of harmful action from gastric or intestinal juices on pancreatic remnant or the Wirsung duct.
\end{abstract}

Keywords: Pancreatoduodenectomy; Pancreaticojejunostomy; Pancreatogastrostomy; Surgical Anastomosis; Suture Material

\section{Introduction}

Pancreatoduodenectomy (PD) was first performed by Kausch one hundred years ago and perfected by Whipple seventy-five years ago. Since that time, the procedure has been further improved upon when new technology and material became available. PD is usually performed as the treatment for pancreatic-biliary-papilla malignancies. For the extent of resection, however, some centers routinely do more extended resection than what is considered standard, i.e., going beyond N1 lymphadenectomy [1]. The most controversial, variable and widely-discussed part of this procedure is the management of the pancreatic remnant, especially since the partner for pancreatic anastomosis could be the small bowel or the stomach [2]. The biliary-enteric anastomosis technique is much less controversial. The success or failure of pancreatic anastomosis is usually measured by the complication rate, especially if the complication is pancreatic fistula. Some factors can be predictors of pancreatic fistula development, i.e., a small pancreatic duct or a soft

${ }^{*}$ Corresponding author. pancreatic texture $[3,4]$. The cause of this might be the fragile tissue parenchyma prone to microinjury during reconstruction. Postoperative pancreatic fistula rate is also proportional to lower hospital volume. Several investigations of pancreato-enteral anastomosis have been performed to assess factors detrimental to pancreatic anastomosis healing. We evaluated the early morphological changes in four patients requiring re-resection after pancreatico-gastro or pancreatico-enteral anastomosis.

\section{Materials \& Methods}

The selected patients were operated on for pancreatic head malignancy (two cases), main duct intraductal papillary mucinous neoplasm (IPMN) (one case) and ampulla of Vater cancer (one case). The patients selection was extraordinary. Only patients who underwent pancreatic resection with pancreatic anastomosis to digestive tract required reoperation and resection of uncomplicated anastomosis was evaluated. Intraoperatively, during this first operation, none of the specimens revealed neoplasmatic cells during microscopic examination of the pancreatic cross sections or an adenomatous polyp of the ampulla as 
per standard protocol. The same specimens were analyzed by a pathologist and revealed foci of cancer cells (two cases), ampulla of Vater cancer within the adenomatous polyp (one case) or invasive ductal carcinoma within the IPMN on the pancreatic duct cut-line (one case). A second operation was planned. The criteria of inclusion resulted in only four cases being enrolled from several surgical centers. None of the patients had a history of local complications related to the pancreatic remnant anastomosis. Age of presented patients varied from 56 to 70 years and there were two males and two females. The second operation was performed between 37 and 114 days after the primary and pancreato-enteral anastomoses were removed en-block with a segment of the digestive tract, details are shown in Table 1. The information of pancreatic parenchyma, transection technique, hemostasis method, sewing material and anastomosis technique was collected in detail, as well as general information about the patient and the OP course.

\section{Light Microscopy}

All hematoxyline/eosine stained

Staining Procedure

1) Deparaffinize sections, 2 changes of xylene, $10 \mathrm{mi}-$ nutes each.

2) Re-hydrate in 2 changes of absolute alcohol, $5 \mathrm{mi}-$ nutes each.

3) $95 \%$ alcohol for 2 minutes and $70 \%$ alcohol for 2 miuntes.

4) Wash briefly in distilled water.

5) Stain in Harris hematoxylin solution for 8 minutes.

6) Wash in running tap water for 5 minutes.

7) Differentiate in $1 \%$ acid alcohol for 30 seconds.

8) Wash running tap water for 1 minute.

9) Bluing in $0.2 \%$ ammonia water or saturated lithium carbonate solution for 30 seconds to 1 minute.

10) Wash in running tap water for 5 minutes.

11) Rinse in $95 \%$ alcohol, 10 dips.

12) Counterstain in eosin-phloxine solution for 30 seconds to 1 minute.

13) Dehydrate through $95 \%$ alcohol, 2 changes of absolute alcohol, 5 minutes each.

14) Clear in 2 changes of xylene, 5 minutes each.

15) Mount with xylene based mounting medium tissueswere reevaluated by two experienced "blinded" pathologists according to criteria mentioned below.

The criteria of evaluation was:

1) Pancreatic parenchyma fibrosis and inflammation.

2) Pancreatic parenchyma compared to primary resection.

3) Suture reaction.

4) Covering with the mucosa.

5) Pancreatic duct healing.

All parameters were established in a scoring scale and checked at a minimum of ten points of location on each slide under a high-power field (HPF).

A foreign body reaction was investigated by measuring the diameter (in $\mu \mathrm{m}$ ) of the perifilamental granuloma at the graft-tissue interface. According to the method described by Conze et al., two granuloma rings were identified [5]. The inner ring represents the inflammatory infiltrate, whereas the outer one represents fibrotic tissue reaction. Five granulomas of each specimen were analyzed under $400 \times$ magnification. Four quadrants of each ring were measured with digital image analyzing software (MultiScan 14.02, Computer Scaning System, Warsaw, Poland) (Figure 1). Total foreign body response was expressed by the mean value of the inner and outer ring diameter separately (five mean values per quadrant per sample) $[3,5]$.

The pancreatic parenchyma specimens were described according to the scoring scale proposed by Niederau [6] (0: no changes, 4: maximal changes. The parameters scored included inflammation, acinar cell vacuolization and acinar necrosis.

Description and scores used for the grading of the pancreatic histologic samples:

1) Edema: 0: Absent; 0.5: Focal expansion of interlobular septae; 1: Diffuse expansion of interlobular septae; 1.5: Same as $1+$ Focal expansion of interlobular septae; 2: Same as $1+$ Diffuse expansion of interlobular septae; 2.5: Same as $2+$ Focal expansion of interacinar septae; 3 : Same as $2+$ Diffuse expansion of interacinar septae; 3.5 : Same as $3+$ focal expansion intercellular spaces; 4: Same as $3+$ Diffuse expansion of intercellular spaces.

2) Inflammation: 0: 0 - 1 perivascular leucocytes/HPF; 0.5: 2 - 5 intralobular leucocytes/HPF; 1: 6 - 10 intralobular leucocytes/HPF; 1.5: 11 - 15 intralobular leucocytes/HPF; 2: 16 - 20 intralobular leucocytes/HPF; 2.5: 21 - 25 intralobular leucocytes/HPF; 3: 26 - 30 intralobular leucocytes/HPF; 3.5: >30 intralobular leucocytes/HPF or focal microabscesses; 4: >35 intralobular leucocytes/HPF or confluent microabscesses.

3) Acinar necrosis: 0: Absent; 0.5: Focal occurrence of 1 - 4 necrotic cells/HPF; 1: Diffuse occurrence of 1 - 4 necrotic cells/HPF; 1.5: Same as $1+$ Focal occurrence of 5 - 10 necrotic cells/HPF; 2: Diffuse occurrence of 5 - 10 necrotic cells/HPF; 2.5: Same as $2+$ Focal occurrence of 11 - 16 necrotic cells/HPF; 3: Diffuse occurrence of 11 16 necrotic cells/HPF (foci confluent necrosis); 3.5: Same as $3+$ focal occurrence of $>16$ necrotic cells/HPF; 4: $>16$ necrotic cells/HPF (extensive confluent necrosis).

4) Vacuolization: 0: Absent, 1: 5\% - 15\% of cells involved, 2: $15 \%-35 \%$ of cells involved, $3: 35 \%-50 \%$ of cells involved, $4:>50 \%$ of cells involved.

5) Fibrosis: 0: Absent; 1: Minimal changes perilobular focal occurrence of loose fibrosis; 2: Mild changes; dense 
Table 1. Four patent characteristic with primary diagnosis and the reason for reoperation and pancreatico-enteral enastomosis resection. Technical details of procedure performed.

\begin{tabular}{|c|c|c|c|c|c|c|c|c|c|c|c|c|}
\hline $\begin{array}{l}\text { Patient } \\
\text { Number }\end{array}$ & Gender & Age & $\begin{array}{l}\text { Distance } \\
\text { between } \\
\text { surgeries }\end{array}$ & $\begin{array}{l}\text { Primary } \\
\text { procedure }\end{array}$ & $\begin{array}{l}\text { Primary } \\
\text { diagnosis }\end{array}$ & $\begin{array}{l}\text { Pancreatic } \\
\text { transection } \\
\text { method }\end{array}$ & $\begin{array}{l}\text { Pancreatic } \\
\text { anastomo- } \\
\text { sis partner }\end{array}$ & $\begin{array}{l}\text { Anasto- } \\
\text { mosis } \\
\text { method }\end{array}$ & $\begin{array}{l}\text { Stitching } \\
\text { material }\end{array}$ & $\begin{array}{l}\text { Hemostasis } \\
\text { method }\end{array}$ & $\begin{array}{l}\text { Reason for } \\
\text { reoperation }\end{array}$ & $\begin{array}{l}\text { Final } \\
\text { specimen } \\
\text { analysis }\end{array}$ \\
\hline 2 & $\mathrm{~F}$ & 56 & 50 days & $\begin{array}{l}\text { Pancreato- } \\
\text { duodenec- } \\
\text { tomy } \\
\text { Pancreato- } \\
\text { jejunostomy }\end{array}$ & $\begin{array}{l}\text { MD IPMN } \\
\& \text { ductal } \\
\text { adenocar- } \\
\text { cinoma }\end{array}$ & scalpel & Jejunum & $\begin{array}{l}\text { Two } \\
\text { layers } \\
\text { single } \\
\text { stitches }\end{array}$ & $\begin{array}{l}\text { Polydioxa- } \\
\text { none } 4 \text { - } 0\end{array}$ & $\begin{array}{l}\text { Selective } \\
\text { stitching \& } \\
\text { Electro- } \\
\text { cautery }\end{array}$ & $\begin{array}{l}\text { Pancreatic } \\
\text { ductal } \\
\text { carcinoma } \\
\text { within MD } \\
\text { IPMN }\end{array}$ & $\begin{array}{l}\text { Wirsung } \\
\text { duct } \\
\text { epithelium } \\
\text { mild } \\
\text { dysplasia }\end{array}$ \\
\hline 3 & M & 61 & 114 days & $\begin{array}{l}\text { Pancreato- } \\
\text { duodenec- } \\
\text { tomy } \\
\text { Pancreato- } \\
\text { jejunostomy }\end{array}$ & $\begin{array}{l}\text { Pancreatic } \\
\text { ductal } \\
\text { adenocanr- } \\
\text { cinoma }\end{array}$ & scalpel & Jejunum & $\begin{array}{l}\text { Two } \\
\text { layers } \\
\text { single } \\
\text { stitches }\end{array}$ & $\begin{array}{l}\text { Polydioxa- } \\
\text { none } 4 \text { - } 0\end{array}$ & $\begin{array}{l}\text { Selective } \\
\text { stitching \& } \\
\text { Electro- } \\
\text { cautery }\end{array}$ & $\begin{array}{l}\text { Pancreatic } \\
\text { ductal } \\
\text { carcinoma } \\
\text { within } \\
\text { cut line }\end{array}$ & $\begin{array}{l}\text { Pancreatic } \\
\text { ductal } \\
\text { cancer } \\
\text { foci } \\
\text { within } \\
\text { pancreatic } \\
\text { remnant }\end{array}$ \\
\hline 4 & M & 69 & 47 days & $\begin{array}{l}\text { Transduode- } \\
\text { nal ampulla } \\
\text { of Vater } \\
\text { resection }\end{array}$ & $\begin{array}{l}\text { Ampulla } \\
\text { of Vater } \\
\text { adenocanr- } \\
\text { cinoma }\end{array}$ & $\begin{array}{l}\text { monopolar } \\
\text { electrocau- } \\
\text { tery }\end{array}$ & $\begin{array}{l}\text { Duode- } \\
\text { num }\end{array}$ & $\begin{array}{l}\text { One } \\
\text { layer } \\
\text { single } \\
\text { stitches }\end{array}$ & $\begin{array}{c}\text { Poliglecap- } \\
\text { rone } 4 \text { - } 0\end{array}$ & $\begin{array}{l}\text { Selective } \\
\text { stitching } \\
\text { \& Electro- } \\
\text { cautery }\end{array}$ & $\begin{array}{l}\text { Primary } \\
\text { diagnosis } \\
\text { adenoma } \\
\text { changed } \\
\text { to invasive } \\
\text { carcinoma }\end{array}$ & $\begin{array}{l}\text { No cancer } \\
\text { cells } \\
\text { within cut } \\
\text { line nor } \\
\text { lymph } \\
\text { nodes }\end{array}$ \\
\hline
\end{tabular}

Four patients MD IPMN: main duct intraductal papillary mucinous tumor, OP: operation.

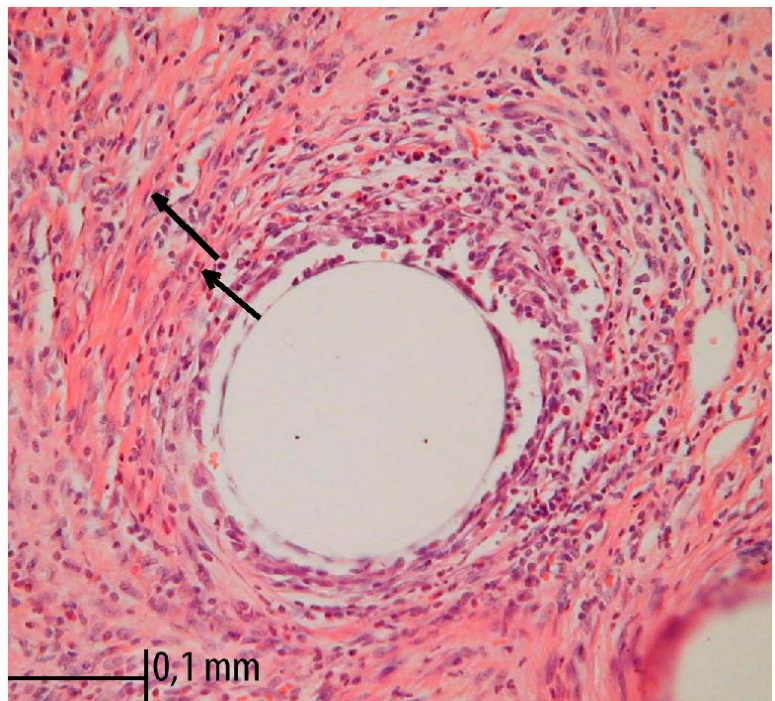

Figure 1. Foreign-body reaction around monofilament polydioxanone stitches. Standard HE staining and 400× magnification in light microscopy. Arrows indicates two rings, the lines divide specimen into 4 quadrants. fibrosis in several perilobular foci; 3: Moderate changes; much dense intralobular diffuse fibrosis; 4: Maximal changes; same as $3+$ diffuse fibrosis between single acini.

6) Hemorrhage and fat necrosis: $0:$ Absent, 0.5: 1 focus, 1: 2 foci, 1.5: 3 foci, $2: 4$ foci, 2.5: 5 foci, $3: 6$ foci, 3.5: 7 foci, $4:>8$ foci.

7) Perivascular and fat necrosis: 0: 0 - 1 perivascular leucocytes/HPF; 0.5: 2 - 5 perivascular leucocytes/HPF; 1: 6 - 10 perivascular leucocytes/HPF; 1.5: 11 - 15 perivascular leucocytes/HPF; 2: 16 - 20 perivascular leucocytes/HPF; 2.5: 21 - 25 perivascular leucocytes/HPF; 3: 26 - 30 perivascular leucocytes/HPF; $3.5:>30$ perivascular leucocytes/HPF or focal microabscesses, 4: $>35$ perivascular leucocytes/HPF or confluent microabscesses.

\section{Results}

During the second operation, there was no evidence of cancer dissemination or local recurrence. All anastomoses were completely healed from a macroscopic point of 
view. There were no intensive fibrosis, rigidity or lesions within the anastomoses. The Wirsung duct was easy to identify in all cases and after longitudinal opening, there were no lesions within the anastomosis segment or proximal to it. All sutures used for duct-to-mucosa stitching were present and in place with minimal loosening of knots (Figures 2(a) and (b)). There were differences, however, from a microscopic point of view of pancreatogastrostomy and pancreato-jejunostomy/duodenostomy. Evidence of regeneration in the columnar-lined mucosa of main pancreatic ducts in all cases of pancreato-enterostomy was observed (Figures 2(a) and (b)). Around the monofilament stitches, the inflammatory foreign-body reaction was present without an evident infection. Pronounced suppurative exudate close to the site of pancreato-gastrostomy was found (Figure 3). Discernible differences in a degree of fibrosclerosis and cellularity of pancreatic stroma depending on the type of surgery was observed (however this could also come from the fibrosis developing during chronic pancreatitis) (Table 2).

Total foreign body reaction varied between $138.1 \mu \mathrm{m}$ and $207.3 \mu \mathrm{m}$. The details of the inflammatory and fibrotic reaction surrounding the thread are shown in Table 3.

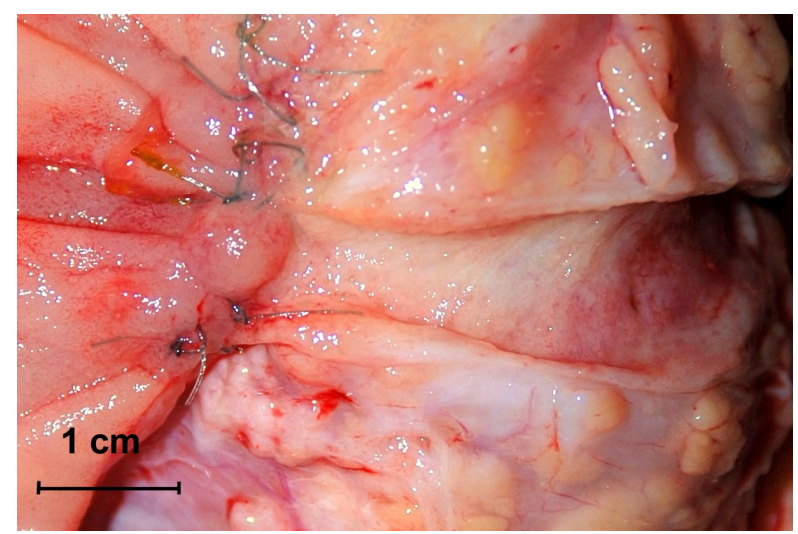

(a)

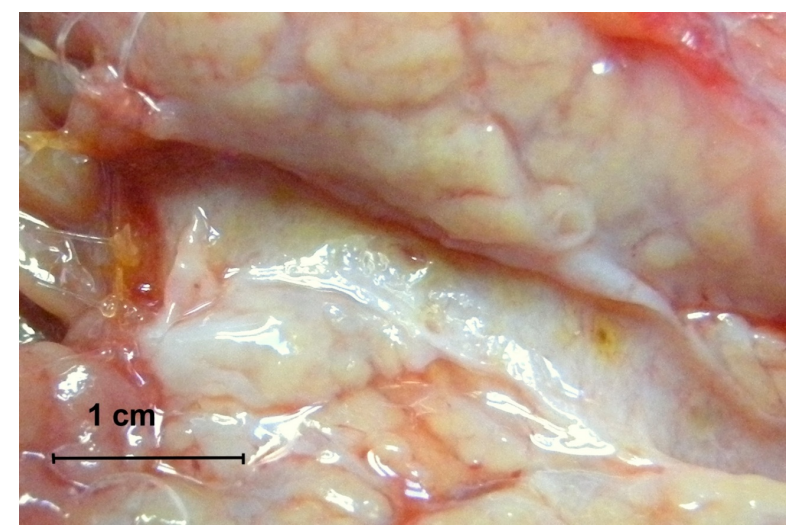

(b)

Figure 2. (a) and (b) Resected specimens-macroscopic presentation. The Wirsung duct is longitudinally opened and the anastomosis line is exposed.

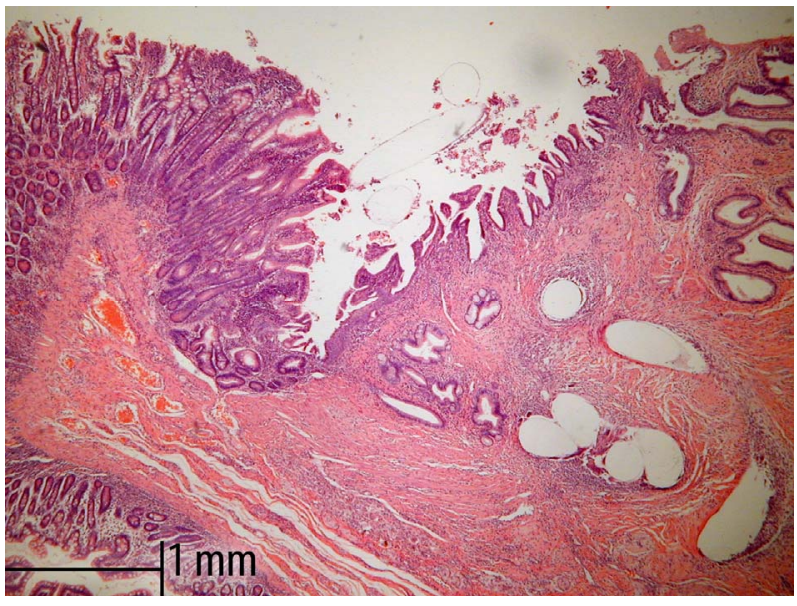

Figure 3. Regeneration in the columnar-lined mucosa of main pancreatic ducts of pancreato-jejunostomy. Standard HE staining and 50 $\times$ magnification in light microscopy.

Table 2. Microscopic changes within pancreatic parenchyma at the anastomosis surface according to the Niederau scoring system.

\begin{tabular}{lcccc}
\hline Parametr & 1 & 2 & 3 & 4 \\
\hline 1) Edema & 0 & 0.5 & 0 & 1.5 \\
2) Inflamation & 3.5 & 4 & 4 & 4 \\
3) Acinar necrosis & 0 & 0 & 0 & 4 \\
4) Vacuolization & 0 & 0 & 1 & 0 \\
5) Fibrosis & 3 & 3 & 2 & 3 \\
6) Haemorrhagic and fat necrosis & 0 & 0 & 1 & 2 \\
7) Perivascular infiltrate & 4 & 4 & 3.5 & 4 \\
\hline
\end{tabular}

Table 3. Microscopic measurement of foreign body reaction surrounding the stitches under $200 \times$ magnification in light microscopy. Values represent the diameter of two rings in $[\mu \mathrm{m}]$ : inner ring-inflammatory reaction, outer ring-fibrotic reaction. All values are Expressem as means from five pools.

\begin{tabular}{ccccc}
\hline Ring $[\mu \mathrm{m}]$ & 1 & 2 & 3 & 4 \\
\hline Inner & $54.1 \pm 56.0$ & $49.2 \pm 21.4$ & $92.3 \pm 57.7$ & $77.3 \pm 56.2$ \\
Outer & $95.6 \pm 29.6$ & $106.0 \pm 39.7$ & $115.0 \pm 36.3$ & $60.8 \pm 9.6$ \\
Sum & 149.7 & 155.2 & 207.3 & 138.1 \\
\hline
\end{tabular}

The pancreatic specimens that were removed were carefully analyzed to estimate the oncological status. The patient with main duct type IPMN had benign lesions with mild dysplasia situated in the resected part and finally underwent pancreatectomy. One patient with pancreatic cancer underwent pancreatectomy and one extended resection with pancreato-gastrostomy. The patient with ampulla of Vater carcinoma underwent standard pylorus preserving $\mathrm{PD}$ with pancreato-jejunostomy. In the last three cases, there were no cancer cells within the removed tissue. In one case, the pathologist found pan- 
creatic cancer infiltration within the resected pancreatojejunostomy (Patient Nr.: 3).

\section{Discussion}

Although the limited pancreatic resection was done in 1683 by Johan Conrad Brunner the modern understanding of pancreatic surgery was provided by gives Walter Kausch and Allen Oldfather Whipple in the of 20th century. Pancreatoduodenectomy is the complex multiorgan resection and digestive tract reconstruction requiring 3 to 5 anastomoses [7].

The idea of the operation was the first large step in pancreatic surgery. One of the first post-op complications was the stitching material. Whipple wrote "I had operated upon a woman with such a tumor, using catgut for the suture and ligature material. The patient died two days later, and the autopsy showed that the catgut had been digested and absorbed by the digestive juices of the pancreas resulting in leakage and peritonitis" [7]. This important observation was the beginning of the challenge in stitching technique and material evolution.

The pancreatic parenchyma is relatively fragile, has no support of muscular wall and stitches are exposed to the enzymatic action. A well-known risk factor of postoperative pancreatic fistula is a soft pancreas [3]. Several data confirm that there is strong association between the frequency of postoperative pancreatic fistula and the hospital volume regardless of the method applied [8]. That observation suggests the material used and handling seems to be crucial for the fate of the pancreato-enteral anastomosis [9].

The group of patients presented here might indicate a defective protocol for conducting intraoperative histological examinations. However, the solution to this problem does not seem to be simple because the local recurrence rate in pancreatic cancer surgery occurs even in R0 resections. In reality, most resections are R1, but upon standard examination, it is not diagnosed. Nonetheless, survival time and local recurrence point to this problem [10].

The time for the second surgery was set according to patient status and preferences. However, the patient reoperated 114 days after primary surgery was delayed due to malnutrition and the estimated high risk of surgery. This patient was intensively fed to improve post-op outcome.

The discussion in the literature concerns the best method of pancreato-enteral anastomosis [1-4,11]. The digestive tract partner, stitching technique and material used are also discussed $[1,9,12]$. However, there is no consensus on any of the mentioned points. Several stitchless techniques are also in preclinical stages $[13,14]$. The main goal for success in the pancreato-enteral anastomosis is to follow the general rules of anastomosis and to not cause pancreatic damage by inappropriate management during the procedure $[4,9]$. Nowadays, the stitching arsenal contains materials with minimal bioreactivity and long lasting degradation time. In experimental studies, the sewing material's exposure to bilio-pancreatic juice shows the immediate disintegration of all kinds of catgut. Silk also presented $17 \%$ reduction in tensile strength. Polydioxanone and polypropylene material shows the maintenance of the tensile strength up to $89 \%$ after 7 days of exposure [15]. The polyfilament thread has a relatively large potential to prevent infection as seen in Patient Nr. 1 [16]. The ideal sewing material should support tissue long enough and not devastate the tissue itself. This feature is especially crucial in the case of pancreatic remnant anastomosis after PD. The experimental data support the benefit of using thin $(4-0$ or $5-0)$ threads and show the least applicable loop tightness [7, 17]. The long-lasting dissolving stitches are in use nowadays with positive effects [1-4,11]. The observation of the described four cases revealed increased epithelial proliferation in all cases of pancreato-enteral anastomosis. During the few weeks that the stitches are in, the small bowel and stomach environment do not produce damage to the pancreatic tissue or to the pancreatic duct. The fine sewing material produces less evident inflammatory response described in experimental studies and confirmed in the presented observation [16]. It might be also argued that the difference in parenchymal infection degree might be related to the kind of anastomosis. Pancreatic anastomosis resection is a radical surgical event. Thus, the number of cases is limited. It would be interesting to evaluate other techniques of pancreato-enteral anastomosis. Autopsy specimen collection and multicenter participation might be of value. The presentation of four cases will not be decisive in any way, but the observations presented here can be informative.

The latest data document the presence of pancreatic juice in peripancreatic exudate without evident leakage from pancreatic duct. The leakage as a result of this "parenchymal injury" after PD could be closely related to the stitching $[17,18]$.

\section{Conclusion}

The four cases presented here support beneficial use of thin monofilament thread for pancreato-enteral anastomosis. There is no evidence of harmful action from gastric or intestinal juice to pancreatic remnant or the Wirsung duct.

\section{REFERENCES}

[1] C. Bassi, M. Falconi, E. Molinari, W. Mantovani, G. Butturini, A. A. Gumbs, R. Salvia and P. Pederzoli, "Ductto-Mucosa versus End-to-Side Pancreaticojeju- nostomy 
Reconstruction after Pancreaticoduodenectomy: Results of a Prospective Randomized Trial," Surgery, Vol. 134, No. 5, 2003, pp. 766-771. doi:10.1016/S0039-6060(03)00345-3

[2] A. Nakao, T. Fujii, H. Sugimoto, T. Kaneko, S. Takeda, S. Inoue, S. Nomoto and N. Kanazumi, "Is Pancreaticogastrostomy Safer than Pancreaticojejunostomy?" Journal of Hepato-Biliary-Pancreatic Sciences, Vol. 13, No. 3, 2006, pp. 202-206. doi:10.1007/s00534-005-1034-8

[3] H. Shinchi, S. Takao, K. Maemura and T. Aikou, "A New Technique for Pancreaticogastrostomy for the Soft Pancreas: The Transfixing Suture Method," Journal of Hepato-Biliary-Pancreatic Surgery, Vol. 13, No. 3, 2006, pp. 212-217. doi:10.1007/s00534-005-1036-6

[4] K. Z'Graggen, W. Uhl, H. Friess and W. M. Buchler, "How to Do a Safe Pancreatic Anastomosis," Journal of Hepato-Biliary-Pancreatic Surgery, Vol. 9, 2002, pp. 733737. doi:10.1007/s005340200101

[5] J. Conze, K. Junge, U. Klinge, C. Weiss, M. Polivoda, A. P. Oettinger and V. Schumpelick, "Intraabdominal Adhesion Formation of Polypropylene Mesh. Influence of Coverage of Omentum and Polyglactin," Surgical Endoscopy, Vol. 19, 2005, pp. 798-803. doi:10.1007/s00464-004-2192-5

[6] C. Niederau, R. A. Liddle, L. D. Ferrell and J. H. Grendell, "Beneficial Effects of Cholecystokinin-Receptor Blockade and Inhibition of Proteolytic Enzyme Activity in Experimental Acute Hemorrhagic Pancreatitis in Mice. Evidence for Cholecystokinin as a Major Factor in the Development of Acute Pancreatitis," Journal of Clinical Investigation, Vol. 78, 1986, pp. 1056-1063. doi:10.1172/JCI112661

[7] J. M. Howard, "Development and Progress in Resective Surgery for Pancreatic Cancer," World Journal of Surgery, Vol. 23, 1999, pp. 901-906. doi:10.1007/s002689900597

[8] N. T. van Heek, K. F. Kuhlmann, R. J. Scholten, S. M. de Castro, O. R. Busch, T. M. van Gulik, H. Obertop and D. J. Gouma, "Hospital Volume and Mortality after Pancreatic Resection: A Systematic Review and an Evaluation of Intervention in the Netherlands," Annals of Surgery, Vol. 242, No. 4, 2005, pp. 781-788. doi:10.1097/01.sla.0000188462.00249.36

[9] A. Kleespies, M. Albertsmeier, F. Obeidat, H. Seeliger, K. W. Jauch and C. J. Bruns, "The Challenge of Pancreatic Anastomosis," Langenbeck's Archives of Surgery, Vol. 393, 2008, pp. 459-471. doi:10.1007/s00423-008-0324-4

[10] M. Hartel, M. N. Wente, S. P. Di, H. Friess and W. M.
Buchler, "The Role of Extended Resection in Pancreatic Adenocarcinoma: Is There Good Evidence-Based Justification?" Pancreatology, Vol. 4, No. 6, 2004, pp. 561566. doi:10.1159/000082181

[11] K. Hakamada, S. Narumi, Y. Toyoki, M. Nara, K. Ishido, T. Miura, N. Kubo and M. Sasaki, "An Easier Method for Performing a Pancreaticojejunostomy for the Soft Pancreas Using a Fast-Absorbable Suture," World Journal of Gastroenterology, Vol. 14, No. 7, 2008, pp. 1091-1096. doi:10.3748/wig.14.1091

[12] M. N. Wente, S. V. Shrikhande, M. W. Muller, M. K. Diener, C. M. Seiler, H. Friess and W. M. Buchler, "Pancreaticojejunostomy versus Pancreaticogastrostomy: Systematic Review and Meta-Analysis," American Journal of Surgery, Vol. 193, No. 2, 2007, pp. 171-183. doi:10.1016/j.amjsurg.2006.10.010

[13] J. Laukkarinen, T. Lamsa, I. Nordback, J. Mikkonen and J. Sand, "A Novel Biodegradable Pancreatic Stent for Human Pancreatic Applications: A Preclinical Safety Study in a Large Animal Model," Gastrointestinal Endoscopy, Vol. 67, No. 7, 2008, pp. 1106-1112. doi:10.1016/j.gie.2007.10.013

[14] I. Nordback, T. Lamsa, J. Laukkarinen, J. Leppiniemi, M. Kellomaki and J. Sand, "Pancreatico-Jejunostomy with a Biodegradable Pancreatic Stent and without Stitches through the Pancrea," Hepatogastroenterology, Vol. 55, 2008, pp. 319-322.

[15] M. A. Muftuoglu, E. Ozkan and A. Saglam, "Effect of Human Pancreatic Juice and Bile on the Tensile Strength of Suture Materials," American Journal of Surgery, Vol. 188, No. 2, 2004, pp. 200-203. doi:10.1016/j.amjsurg.2003.12.068

[16] K. N. Leknes, K. A. Selvig, O. E. Boe and U. M. Wikesjo, "Tissue Reactions to Sutures in the Presence and Absence of Anti-Infective Therapy," Journal of Clinical Periodontology, Vol. 32, No. 2, 2005, pp. 130-138. doi:10.1111/j.1600-051X.2005.00647.x

[17] T. Lamsa, H. T. Jin, P. H. Nordback, J. Sand and I. Nordback, "Effects of Diameter, Number and Tightness of Sutures on Pancreatic Injury Response," Digestive Surgery, Vol. 25, No. 4, 2008, pp. 269-277. doi: $10.1159 / 000135604$

[18] J. H. Nguyen, "Distinguishing between Parenchymal and Anastomotic Leakage at Duct-to-Mucosa Pancreatic Reconstruction in Pancreaticoduodenectomy," World Journal of Gastroenterology, Vol. 14, No. 43, 2008, pp. 66486654. doi: $10.3748 /$ wjg. 14.6648 